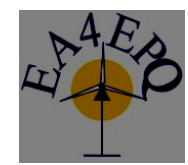

International Conference on Renewable Energies and Power Quality (ICREPQ'14)

Cordoba (Spain), $08^{\text {th }}$ to $10^{\text {th }}$ April, 2014

Renewable Energy and Pourer Quality. Fournal (RE\&PQJ)

ISSN 2172-038 X, No.12, April 2014

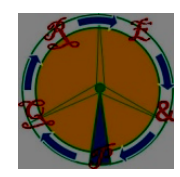

\title{
Energy Efficiency Evaluation of Materials Applied in Core of Three Phase Planar Actuator Through Reduced Model
}

\author{
Meto J. M. ${ }^{1-2}$, Sebastião, L.M ${ }^{1}$,Ferreira C.A ${ }^{1}$, Ando Junior, O. H. ${ }^{1-2}$,Spacek, A. D. ${ }^{1-2}$, Malfatti, C. F. ${ }^{2}$, Schaeffer, L. ${ }^{2}$ \\ ${ }^{\mathbf{1}}$ Department of Electrical Engineering \\ SATC, Beneficent Association of Santa Catarina Coal Industry \\ Street Pascoal Meller, 73. Criciúma-SC (Brazil) \\ Phone/Fax number: +55 48 3431-75.50, e-mail: joao.neto@ satc.edu.br, criciuma@ laboratorioderobotica.com \\ carlos.ferreira@satc.edu.br, oswaldo.junior@satc.edu.br,anderson.spacek@satc.edu.br, \\ ${ }^{2}$ School of Engineering \\ UFRGS, Federal University of Rio Grande do Sul \\ Av. Osvaldo Aranha, 103. Porto Alegre-RS (Brazil) \\ Phone/Fax number: +55 51 3308-31.29, e-mail: celia.malfatti@ufrgs.br, schaefer@ufrgs.br
}

\begin{abstract}
The purpose of this work is evaluate properties of SMC Composites applied to construct cores of Three-phase Planar Actuator (T.P.A.) such as other eletromagnetic devices. The high magnetic permeability and electrical resistivity - characteristics of SMC provides advantages when compared to conventional materials. It is possible to manufacture machines with low energy consumption and higher yield. Thus, this article presents performance parameters between different materials used in construcion of T.P.A obtained by simulation of its reduced model. By using the reduced model for R\&D of T.P.A. minimizes costs related to manufacturing of prototypes with maintance the complete model's main eletromagnetic characteristics.The simulations was made based in 16 configurations changing materials and operation frequencies. With numerical results of: solid loss, linear and normal forces under the same current excitation. The best results was obtained with the combination: Somaloy, Aluminium and $30 \mathrm{~Hz}$.
\end{abstract}

\section{Keywords}

Three-phase Planar Actuator, powder metalurgy, energy consumption, soft magnetic composite (SMC.)

\section{Introduction}

The characteristics of new composite materials obtained from powder metallurgy are very useful in applications of electrical engineering, especially in development of machines based in magnetic field variations.

Soft Magnetic Composite (SMC) materials as ferrite somalloy, permalloy, and others - with high magnetic permeability - provides advantages when compared to conventional materials. It is possible to manufacture machines with low energy consumption, size and higher performance. Since these composite liable to be used in the manufacture of core planar electric actuators.

Researches presents the Three-phase Planar Actuator (T.P.A.) as an traction element capable to be used in bidirectional movements executed by a single mechanism.
With higher efficiency compared to the usual mechanical arrangements based in rotary engines, gears and shafts. These mechanical systems produces large power transmission's loss, severe wear - due to friction of the mechanical parts even with the use of low viscosity fluids for lubrication - which increases operating costs, mainly relating to maintenance.

However sought to optimize processes, materials and equipment aiming the development process. Reduced model becomes less expensive and easier to manufacture. Minimizing the high costs associated with engineering and metal composite used in the manufacturing of prototypes to validate the simulations.

Thus, the article presents results by simulations with finite element method software to evaluate the performance of different materials applied in the core of the T.P.A. through its reduced model - which represents $33 \%$ of the original size.

There's increasing interest observed in these materials development due to advances in metallic composite and processes related to area of powder metallurgy aiming highest yield, efficiency and lower costs. Associated with the substantial increase in research of linear electric machines, especially for industrial and transportation applications, based on electromagnetic phenomena; the increasing interest in these devices is intimately connected to the emergence of new materials and constant modernization of control techniques dictated by more efficient dedicated systems.

\section{Projection of Electricity Consumption}

Economic growth in the countries have in common the need for energy resources as a basis for increasing the productive sector . Sustainable development is a relevant factor in the analysis of this expansion, minimizing the environmental impact that man has on the planet.

In terms of energy supply, electricity is one of the most versatile and convenient forms of energy, and has become a vital and strategic resource for socio-economic 
development of countries [1].

At the same time the electricity promotes the evolution and development of a country, the development requires more electricity. According to data from the Brazilian Electric Power SA (Eletrobrás), the electricity consumption in Brazil grew more than $1,100 \%$ in the last 40 years at an average rate of $6.75 \%$ per annum. The most significant growth occurred in the $70 \mathrm{~s}$, a period called the "Economic Miracle ", where the energy consumption grew at rates of over $10 \%$ per year. In Brazil, the public service is the major contributor, with $87.7 \%$ of the total generation, where most of it is generated from hydropower[2] [3].

Table 1 shows the projection from 2012 to 2015 , where all types of consumers, and these include : industrial, residential, commercial, rural, public lighting and public services. Thus, we see an average annual growth of $4.87 \%$ in the low national growth and $4.5 \%$ in the high scenario [2].

Table 1 - Projection electricity consumption in Brazil

\begin{tabular}{|c|c|c|c|c|}
\cline { 2 - 5 } \multicolumn{1}{c|}{} & $\mathbf{2 0 1 2}$ & $\mathbf{2 0 1 3}$ & $\mathbf{2 0 1 4}$ & $\mathbf{2 0 1 5}$ \\
\hline Low Demand(GWh) & 460.443 & 478.002 & 503.783 & 531.798 \\
\hline High Demand(GWh) & 467.118 & 485.776 & 513.017 & 542.525 \\
\hline
\end{tabular}

It is estimated that more than two thirds of the total electricity generated in an industrialized country such as the United States is consumed by electric motors.[4] With this induction motors, are important parts in the analysis of energy savings.

Since the part of the electric power to the rotary electric motor, boost the search for constructive and new conceptions of alternative motor. Those with higher energy performance, can they positively impact on the future energy scenario, minimizing the need for new plants generating electricity through pollution sources.boost

\section{A Three Phase Planar Actuator with two Degrees of Freedom and its reduced model}

The Three-phase Planar Actuator (T.P.A.) configures itself as an electromagnetic device with movement on a plane with two degrees of freedom from a single traction device. It consists of a car which has two independent Three-phase windings orthogonal each other (one along in the $\mathrm{x}$-axis another in the $\mathrm{y}$-axis) constructed on a ferromagnetic core translador, and a stator formed by an aluminum plate constructed over a ferromagnetic core (see figure 1).

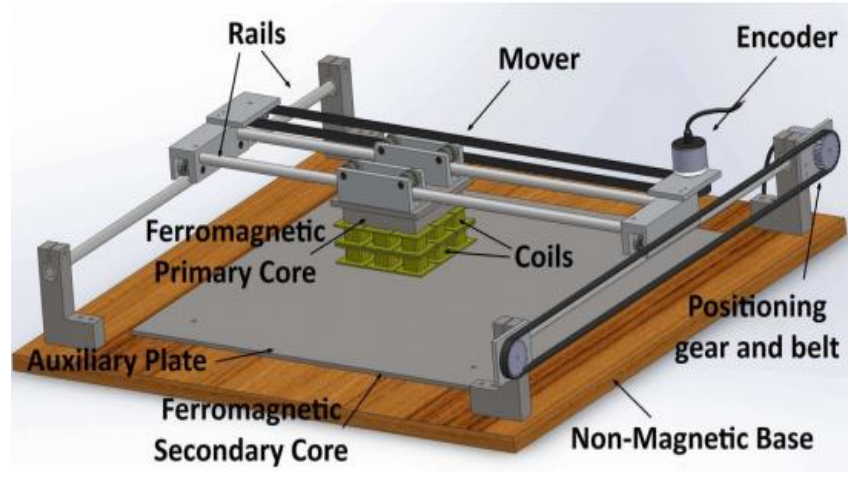

Fig. 1. Perspective view of the actuator and its parts[5]
The primary element (concerns the mover part) is mounted with an ferromagnetic single core constructed with 9 equal teeth. Each teeth has 2 coils referring one per different winding. The upper coils are for $\mathrm{X}$ axis translation and lower for $\mathrm{Y}$ axis movement. When supplied with three-phase sinusoidal balanced current (with $2 \mathrm{pi} / 3$ radians phase delay each other) it produces an traveling field who induces electrical current in secondary auxiliary plate (like conventional induction motors). The interation of induction current and traveling field produces linear forces in 2 axes. Giving two degrees of freedom for this device.

About the materials, the primary core must be ferromagnetic with low conductivity and high magnetic permeability such as secondary core. The auxiliary plate (thin, with a maximum around $1 \mathrm{~mm}$ ) is purposely mounted in airgap location (between primary and secondary cores) to give an low impedance way for induced currents.

This study proposes evaluate efficiency responses when changing primary core material, secondary auxiliary plate material and frequency operation. The SMC Somaloy 500 - produced by Swedish company Högänas - has a high magnetic permeability allied with a low electric condutivity was applied in primary core in comparison with Steel1010 common core. The auxiliary plate originally made by aluminium - was suposed to be made with copper, which has a better electric condutivity for secondary currents.

However, the original complete model for mover primary core is expensive and hard to construct in a single block. For avaliative simulations and real expriments to performance indicative analisys, a reduced model was created. It has $33 \%$ of total mounting and allows to energize with three-phase current. The response of reduced model for alterations and configurations represents directly the complete model based on partial analysis - such as superposition technique in electric systems.

\section{Numerical Analysis of the Reduced Model}

The model inserted into the finite element software is compound by primary formed from a single block, with electrical isolation between it and the coils. The coils are made up of copper, each winding with 250 spirals, with two coils for tooth. The superior coils was for displacement $\mathrm{x}$-axis. The lower coils - originally projected for $y$-axis movement - was conected in series with superior ones. Resulting in 500 spirals each widing and each teeth. Fed with balanced three-phase sinusoidal alternating current, this device has only one degree of freedom, but based in the same functioning principle of complete model.

It was used in simulation of the reduced model the core made by Steel1010, due to the ease of this machining material; and Somaloy 500, a magnetically soft ferromagnetic metals composite applies for use in low frequencies in the order of up to $400 \mathrm{~Hz}$, for having low magnetic losses totals that range. 
The amount of addition of lubricants and/or binders in metal powder, followed by compaction and thermal treatment determines the magnetic properties of composite. Which have to satisfy requisites from electrical and mechanical equipment objectivized for use in this type of application [6] [7]. In the stator the auxiliary sheets of aluminum and copper was maintained to evaluate the influence of these materials on the overall performance of the mechanism.

For simulations, the reduced model was inserted in finite-element method software with all relevant characteristics. A single-core with 3 teeth and 2 coils with 250 spiral windings each one totaling 500 spirals each ledge (see figure 2).

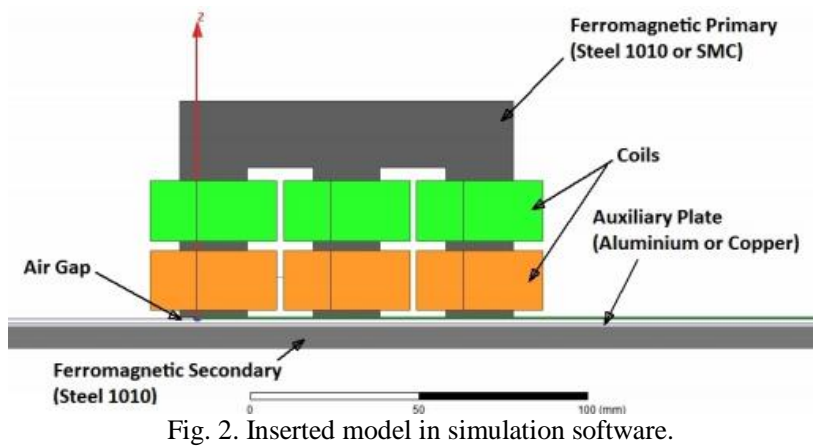

For winding feeding, the current was arbitrary chosen in 3A for each phase, with Y three-phase of coils connection. Figure 3 shows how it was made.

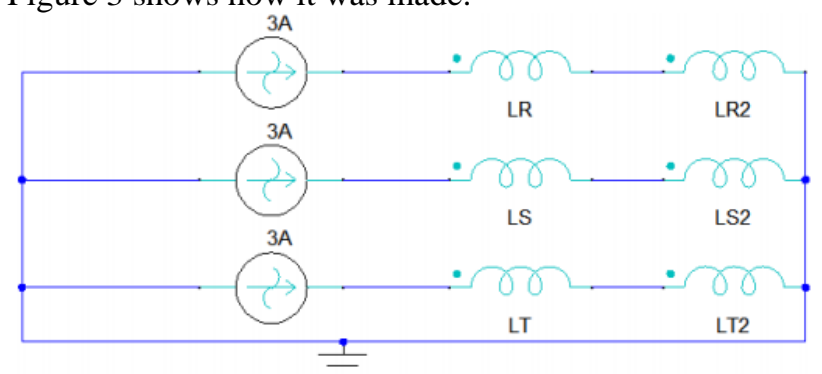

Fig. 3. Feeding schematic circuit.

Where: LR, LS, and LT was the upper coils and LR2, LS2, and LT2 was the lower coils for R, S and T phases respectively. In all simulations the $3 \mathrm{~A}$ was maintained just matherials or operation frequencies was changed.

The setup configuration of simulations was established according to operating frequency to gives responses for 2 complete cycles of first phase with approximately $20^{\wedge}-1$ of period for time step setting. The results was obtained by graph mode - as seen on figure 4 - and the calculated mean was used for its discussion.

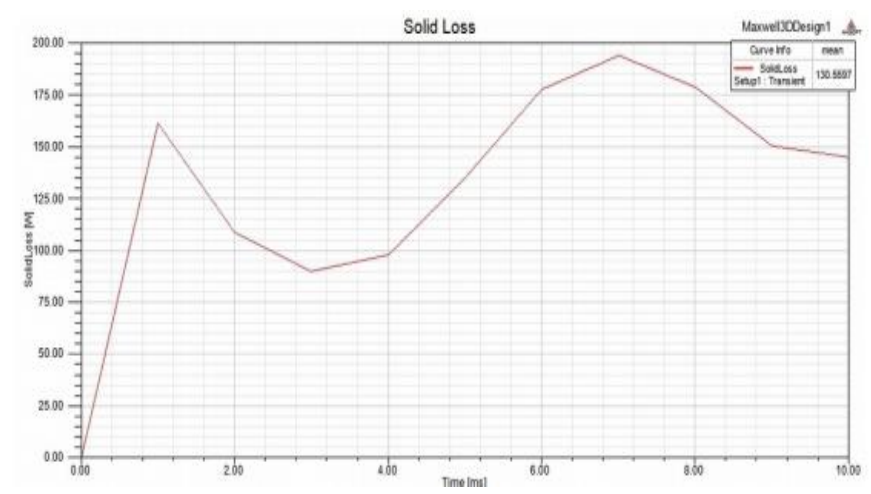

Fig. 4. Solid Loss graph with Steel1010, Aluminium and 90Hz.

\section{Results and Analisys}

For proper performance analysis, the obtained data was related with input current and some coefficients was calculated to facilitate its evaluation and comparison.

Thre parameters was created:

- $1^{\text {st }}$ Parameter $-\mathrm{X}$ Force $(\mathrm{Fx})$ by current: This parameter divides $\mathrm{x}$-axis intensity force by fed current module. as higher the resulting force by current increment, better final response (principal objective for T.P.A.)The higher this parameter, good for machine's performance.

- $2^{\text {nd }}$ Parameter $-\mathrm{Z}$ Force $(\mathrm{Fz})$ by current: When dividing $\mathrm{Z}$ force magnitude with injected current, it gives a parameter about the normal force due to equipment energizing. As a unwanted response, $\mathrm{Z}$ Force overloads the mechanical structure and doesn't any useful work. The lower this parameter, good for machine's performance

- $3^{\text {rd }}$ Parameter - Solid Loss by current: When applying the same operation with solid loss, a ratio of ohmic losses by ampere feeding is calculated. This loss overheat the device and its not applied in operational work. The lower this parameter, also good for machine's performance. The obtained simulation results was plotted as column graphics as seen on figures 5-7.

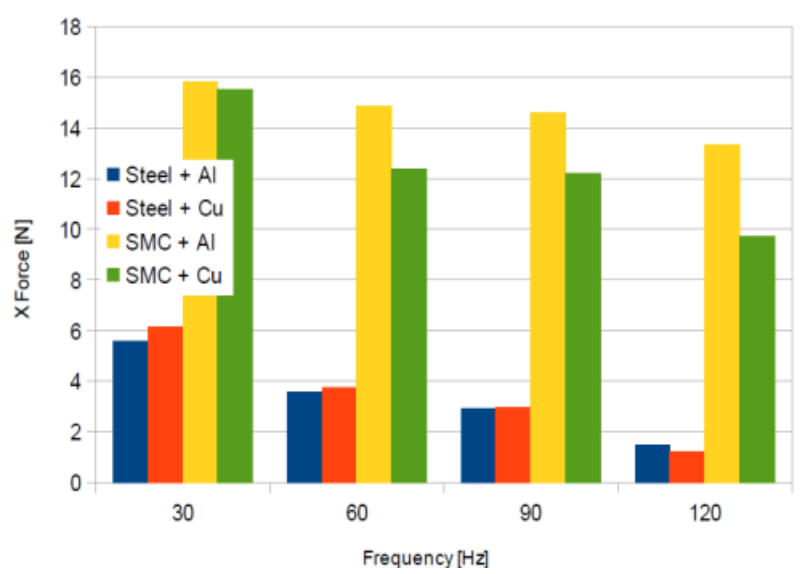

Fig. 5. X Force results.

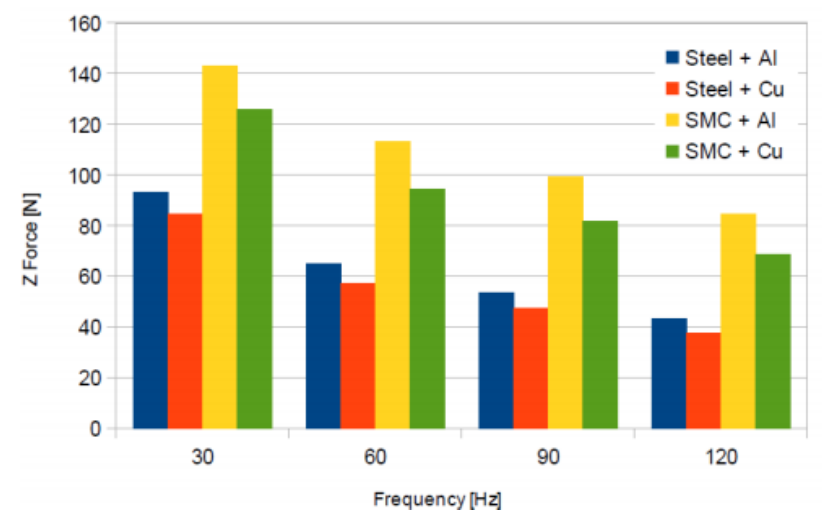

Fig. 6. Z Force results.

The construction of Figure 7 was based on the analysis of average losses in solid entire device. It is possible to see improvement when the material of the gap is replaced by copper frequencies from $60 \mathrm{~Hz}$ to either of the two ferromagnetic core materials used in the primary. 


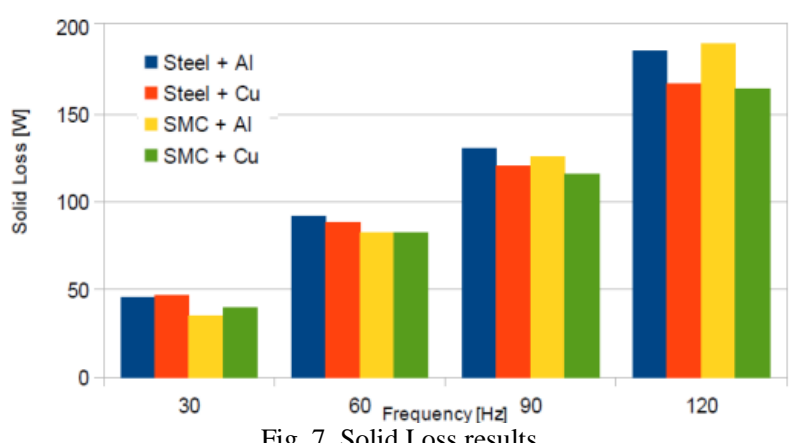

Fig. 7. Solid Loss results.

About calculated coefficients, a general coefficient (G.C.) was equationed. The equation 1 shows how it was made.

$$
\text { G.C. }=\frac{C 1^{2}}{C 2 \cdot C 3}
$$

Where: G.C. = General Coefficient [N/W]

$$
\begin{aligned}
& \mathrm{C} 1=1^{\text {st }} \text { Coefficient }[\mathrm{N} / \mathrm{A}] \\
& \mathrm{C} 2=2^{\text {nd }} \text { Coefficient }[\mathrm{N} / \mathrm{A}] \\
& \mathrm{C} 3=3^{\text {rd }} \text { Coefficient }[\mathrm{W} / \mathrm{A}]
\end{aligned}
$$

An comparative table was made with all calculated coefficients, and it shows the best response configurations and its respective coefficients. (see figure 8)

$\begin{array}{llccccc}\text { Prim. Material } & \text { AG Material } & \mathrm{F}[\mathrm{Hz}] & \mathrm{Fx} /[[\mathrm{N} / \mathrm{A}] & \mathrm{Fz} /[\mathrm{NNA}] & \text { Loss/l [W/A] } & \text { Gen. Coefficient } \\ \text { Steel 1010 } & \text { Aluminium } & 30 & 1,8621 & 31,0532 & 15,1945 & 0,7349 \\ \text { Steel 1010 } & \text { Copper } & 30 & \mathbf{2 , 0 5 1 1} & \mathbf{2 8 , 2 0 3 0} & \mathbf{1 5 , 5 7 5 9} & \mathbf{0 , 9 5 7 7} \\ \text { Somaloy } & \text { Aluminium } & 30 & \mathbf{5 , 2 6 4 1} & \mathbf{4 7 , 6 4 1 2} & \mathbf{1 1 , 6 3 7 1} & 4,9983 \\ \text { Somaloy } & \text { Copper } & 30 & 5,1740 & 41,9133 & 13,1633 & 4,8522 \\ \text { Steel 1010 } & \text { Aluminium } & 60 & 1,1933 & 21,6743 & 30,6185 & 0,2146 \\ \text { Steel 1010 } & \text { Copper } & 60 & 1,2453 & 19,1067 & 29,4051 & 0,2760 \\ \text { Somaloy } & \text { Aluminium } & 60 & 4,9456 & 37,7497 & 27,4648 & 2,3591 \\ \text { Somaloy } & \text { Copper } & 60 & 4,1228 & 31,4333 & 27,4163 & 1,9723 \\ \text { Steel 1010 } & \text { Aluminium } & 90 & 0,9768 & 17,9001 & 43,5199 & 0,1225 \\ \text { Steel 1010 } & \text { Copper } & 90 & 0,9861 & 15,7261 & 40,2010 & 0,1538 \\ \text { Somaloy } & \text { Aluminium } & 90 & 4,8662 & 33,0769 & 42,0344 & 1,7032 \\ \text { Somaloy } & \text { Copper } & 90 & 4,0693 & 27,2088 & 38,5337 & 1,5794 \\ \text { Steel 1010 } & \text { Aluminium } & 120 & 0,4970 & 14,3843 & 62,1562 & 0,0276 \\ \text { Steel 1010 } & \text { Copper } & 120 & 0,4021 & 12,5253 & 55,8192 & 0,0231 \\ \text { Somaloy } & \text { Aluminium } & 120 & 4,4422 & 28,1390 & 63,5426 & 1,1036 \\ \text { Somaloy } & \text { Copper } & 120 & 3,2392 & 22,8966 & 54,9431 & 0,8341\end{array}$

Fig. 8. Coefficients table.

The analysis of figure 9 indicates a substantial improvement in performance when using the primary SMC, and the content of the decaying trend with increasing operating frequency.

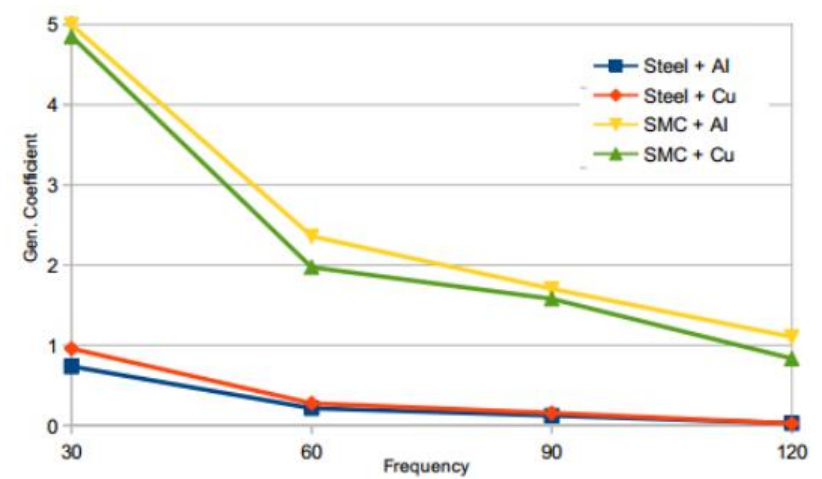

Fig.9. Coefficient General (Gen. Coefficient) for the 16 possibilities evaluated.

Based on information obtained in the simulations, there is an increase in performance desired response (linear force acting planar - Fx) when applied in the SMC translador API In absolute terms, it is possible to still verify the increase in more than 8 times the force planar when the operating frequency is located at $120 \mathrm{~Hz}$, according to equation 1 .

$$
\frac{\text { Force }(\text { SMC })}{\text { Force }(\text { Steel } 1010)}=\frac{13,3267}{1,4911}=8,9375
$$

\section{Where: Operating Frequency $=120 \mathrm{~Hz}$ Auxiliary Plate Material = Alumínio}

\section{Final Considerations}

The use of numerical analysis in the reduced model of the Three phase actuator allows us to evaluate different configurations of materials with a lower operating cost, machining time and development. The current model entered into the software, previously validated by previous studies, provides important indications for making decisions before building physical prototypes of electrical machines in linear development.

The inclusion of copper in place of aluminum, combined with application of SMC in the construction of translador allowed to evaluate performance parameters to verify the economic feasibility of production of physical prototypes with such configurations. The reduced model obtained better responses with SMC configuration, using a $30 \mathrm{~Hz}$ Aluminum with general parameter calculated at 4.9983 [A / W].

The 8 times better performance with SMC cores means that we can use 8 motors with a consumption of one (with actual technologies). In a pessimist perspective it's possible to consider 2 times better the SMC response. Applying this indicative in world's energy demand where is estimated that around $2 / 3$ of generated energy is consumed by electrical motors - the results gives optimistic prognosis in reducing energy consumption.

\section{References}

[1] Atlas da Energia Elétrica no Brasil. Brasília: Agência Nacional de Energia Elétrica, n. 2, 2005. Disponível em: <http://www.aneel.gov.br/aplicacoes/Atlas/down load.htm>. Acesso em: 17 abr. 2013.

[2] REGO, E. E. Avaliação de viabilidade de um empreendimento de geração de energia hidrelétrica. 2004. 129 f. Monografia (Bacharel em Ciências Econômicas). Universidade de São Paulo. São Paulo 2004.

[3] Balanço Energético Nacional. Brasil 2010. Disponível em: < https://ben.epe.gov.br/downloads/Relatorio Final BEN 2010.pdf> Acesso em: 29 mai. 2011.

[4]Bin Lu, (2006). Energy usage evaluation and condition monitoring for electric machines using wireless sensor networks. Ph.D. dissertation, Georgia Institute of Technology.

[5] BAGGIO FILHO, Nolvi Francisco; FLORES FILHO, Aly Ferreira. An Analysis on Electric and Magnetic Behaviour on an Induction Planar Actuator. Journal Of Microwaves, Optoelectronics And Electromagnetic Applications, Brazil, v. 12, n. 1, p.37-48, jun. 2012.

[6] FLORES FILHO, Aly F.; BAGGIO FILHO, Nolvi F.. Analysis of an Induction Planar Actuator. XIX International Conference On Electrical Machines, Rome, p.978-984, 2010.

[7]SHOKROLLAHI, H. \& JANGHORBAN, K. 2007. Soft magnetic composite materials Journal of Materials Processing Technology, London (UK), Vol. 189,1-12 (Classificação SMC)

[8] ESSWEIN JUNIOR, Jorge Alberto Lewis. Desenvolvimento de Compositos Magnéticos Macios Utilizados em Núcleos de Máquinas Elétricas. 2009. 117f. Dissertação - Departamento de Pós-graduação em Engenhara de Minas, Metalúrgica e de Materiais - PPGEM. Universidade Estadual de Campinas. Porto Alegre. 2009. 